\title{
INSTANTANEOUS WAVE-FREE RATIO (IFR) CAN DETECT IMPROVEMENT IN CORONARY STENOSIS SEVERITY AFTER PERCUTANEOUS INTERVENTION
}

S S S Nijjer, ${ }^{1}$ S Sen, ${ }^{1}$ R Petraco, ${ }^{1}$ F Cuculi, ${ }^{2}$ C Broyd ${ }^{1}$ R A Foale, ${ }^{3}$ I S Malik, ${ }^{3}$ G W Mikhail, ${ }^{3}$ A S Sethi, ${ }^{3}$ R R Kaprielian, ${ }^{3}$ C S R Baker, ${ }^{3}$ A D Hughes, ${ }^{1}$ D P Francis, ${ }^{1}$ J Mayet, ${ }^{1}$ R K Kharbanda, ${ }^{2}$ C Di Mario, ${ }^{1}$ J E Davies ${ }^{1}{ }^{1}$ Imperial College London; ${ }^{2}$ John Radcliffe Hospital; ${ }^{3}$ Hammersmith Hospital

doi:10.1136/heartjnl-2013-304019.54

Background The instantaneous wave-Free Ratio (iFR), a pressure-only adenosine-free index of coronary stenosis severity has been evaluated as a diagnostic tool in the ADVISE trial and registry. However, it is unknown whether iFR can detect improvement in stenosis significance immediately after percutaneous coronary intervention (PCI). We sought to compare the change in iFR and FFR immediately after PCI.

Method 69 coronary lesions (63 patients, mean age $63 \pm 10 ; 71 \%$ male; $53 \%$ smokers; $22 \%$ diabetics) with FFR $\leq 0.80$ undergoing elective PCI had intra-coronary pressures measured at rest and during adenosine-mediated vasodilatation $(140 \mu \mathrm{g} / \mathrm{kg} / \mathrm{min})$. Measurements were repeated after PCI. iFR and FFR values were calculated offline using fully automated algorithms. iFR is calculated at rest over five heart beats, as a ratio of distal to proximal coronary pressures over the wave-free period in diastole.

Results The mean diameter stenosis was $64 \pm 15 \%$ by quantitative coronary angiography. Pre-PCI, the mean FFR was $0.68 \pm 0.12$ and the mean iFR was $0.76 \pm 0.19$. After PCI both FFR and iFR increased significantly compared to baseline (FFR 0.88 \pm 0.07 , $\mathrm{p}<0.001$; iFR $0.93 \pm 0.06, \mathrm{p}<0.001)$. The incremental improvements $\Delta$ FFR $0.20 \pm 0.14$ and $\Delta$ iFR $0.18 \pm 0.19$ were not statistically different $(p=0.49)$. Furthermore, diabetic and smoking status did not affect the magnitude of the incremental change for either FFR (diabetes $p=0.79$; smoking 0.62 ) or iFR ( $p=0.62$ and 0.92 respectively). Conclusion Following PCI, iFR measured at rest can detect changes in lesion severity. The change in $\mathrm{iFR}$ is similar in magnitude to that observed with FFR after PCI, and is similar in diabetic and non-diabetic subjects. This suggests iFR has potential to objectively measure the improvement in coronary haemodynamics following PCI. 